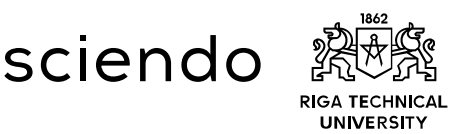

ISSN 2256-0394 (online)

ISSN 2256-0386 (print)

2018, 32, 149-159

doi: $10.2478 / \mathrm{eb}-2018-0012$

https://www.degruyter.com/view/j/eb

\title{
HEDGING EFFECTIVENESS FOR INTERNATIONAL INDEX FUTURES MARKETS
}

\author{
Alexandros KOULIS ${ }^{1 *}$, George KAIMAKAMIS ${ }^{2}$, Christina BENEKI ${ }^{3}$ \\ ${ }^{1,3}$ Department of Business Administration, Technological Institute of Ionian Islands, \\ Greece \\ ${ }^{2}$ Hellenic Army Academy, Greece \\ Corresponding author e-mail: koulisal@gmail.com
}

\begin{abstract}
This paper investigates the hedging effectiveness of the International Index Futures Markets using daily settlement prices for the period 4 January 2010 to 31 December 2015. Standard OLS regressions, Error Correction Model (ECM), as well as Autoregressive Distributed Lag (ARDL) cointegration model are employed to estimate corresponding hedge ratios that can be employed in risk management. The analyzed sample consists of daily closing market rates of the stock market indexes of the USA and the European futures contracts. The findings indicate that the time varying hedge ratios, if estimated through the ARDL model, are more efficient than the fixed hedge ratios in terms of minimizing the risk. Additionally, there is evidence that the comparative advantage of advanced econometric approaches compared to conventional models is enhanced further for capital markets within peripheral EU countries.
\end{abstract}

Keywords: Minimum Variance, Hedge Ratio, Effectiveness

JEL Classification: G11, G13

\section{INTRODUCTION}

Financial markets have been highly volatile and highly complex in recent decades. As a result, the determination of optimal hedge ratios has emerged as the main subject of discussion for the academic community, but also the subject of monitoring by the majority of financial institutions, investors and businesses. The problem that arises relates to the number of futures that the investor could hold for each underlying unit in order to protect its portfolio against any undesirable market movements. The main objective of the paper is the direct comparison, through a trading strategy process, of the forecasting ability of several econometric approaches that account for the hedging effectiveness. Hedging through trading futures is a common process which is used to control or even reduce the risk of adverse price movements. According to Pennings and Meulenberg (1997), a decisive factor in explaining the success of futures contracts is their hedging effectiveness.

The purpose of this study is to determine whether the parameters that determine the share distribution pattern are significantly influenced by the information available on the market and, consequently, to determine the hedge ratio more 
effectively. The work calculates the hedge ratios with three alternative econometric methods: Ordinary Least Square Model (OLS), Error Correction Model (ECM) and Autoregressive Distributed Lag cointegration model. It also assesses the effectiveness of alternative risk hedging methods by comparing the risk-benefit ratio by minimal variance, ie minimizing portfolio fluctuations. The hedge ratio is calculated by the fraction of the number of units traded in the futures market over the number of units traded in the spot market. The investor's objectives determine the required hedging strategies. The empirical findings of the paper suggest that more advanced econometric approaches could potentially enhance the effectiveness of the hedging process.

\section{LITERATURE REVIEW}

One of the most important theoretical issues in Risk Management is finding the optimal risk hedge ratio. The question is to find the optimal method so that investors are protected against possible undesirable market movements at the lowest possible cost. In the literature, the first model was developed by Johnson (1960) and then improved by Ederington (1979) who minimized the variation of the total portfolio using the Ordinary Least Square Method (OLS). However, Park and Bera (1987), as well as Herbst, Kare and Caples (1989) questioned about the importance since it does not take into account the heteroskedasticity that exists between the underlying title and the futures contract. Criticism has also been extended to the fact that the hedge ratios of an OLS model are static, that is, they do not take into account the variability in time-bound variance as well as the alteration of other parameters such as curvature and symmetry. Then, for more effective estimation of hedge ratios, more complex models were used, such as ARCH, GARCH, (Baillie \& Myers, 1991; Cecchetti \& Cumby, 1988) and cointegration models (Chou, Denis \& Lee, 1996; Ghosh, 1993; Lien \& Luo, 1993). Baillie \& Myers (1991) compare GARCH type with time hedge ratios with hedge ratios and find that hedge ratios are heavier in relation to hedge ratios. These studies ignore the investment profile, which should be taken into account. Ghosh (1993) finds that the minimum variance hedge ratio is underestimated as a result of the wrong model when the combined relationship of futures and underlying securities is not taken into account, and hence error correction is not included in regression. Lien and Luo (1994) argue that cointegration should be taken into account when comparing the ex-post effectiveness of the various hedging strategies.

On the other hand, Lien and Luo (1993) minimized the mean extended Gini coefficient (MEG) in order to find the optimal hedge ratio. Shalit (1995) proved that the hedge ratio which becomes from the MEG approach is identical to the hedge ratio that becomes from the mean-variance approach, when the common distribution of spot and futures returns is normal. Lien and Tse $(1998,2000)$ and Chen, Lee and Shrestha (2001) in order to estimate the optimal hedge ratio, minimized the generalized semi variance (GSV).

Lien and Tse (1998) in their study found that the GSV hedge ratio is the same as the mean-variance hedge ratio, when the following criteria co-exist: if spot and future prices are normally distributed and if the future prices follow a martingale 
process. Chen, Lee and Shrestha (2001) developed the GSV hedge ratio to the Mean-GSV hedge ratio. Switzer and El-Khoury (2007) proved that when non symmetry of extreme volatilities is taken in consideration, the hedging performance is improved. A year earlier, Norden (2006) studied the significantly increase of hedging efficiency after the futures split.

Chou, Denis and Lee (1996) used data from the Japan's Nikkei Stock index futures by taking in account different time intervals. Through this method he managed to estimate and compare the hedge ratios between the conventional model and the EC model. Lee, Wang and Chen (2009) used data from international markets like Korean, Singapore, Japan, Taiwan, Hong Kong and United States in order to examine four static and one dynamic hedging model. Their aim was to find the optimal hedge ratio.

During the Asian financial crisis and post-crisis Wang and Hsu (2010) studied the hedge ratio stability of the index futures contracts of Hong Kong, Japan, and Korean. Furthermore, Sah and Pandey (2011) used three models in order to estimate the effective hedge ratio and its hedging effectiveness. His daily data were taken from S\&P CNX Nifty futures. Juhl, Kawaller and Koch (2012) used a simple regression on price changes and an error correction model (ECM) in order to find hedge effectiveness. His empirical study proved that when the prices of the hedged item and the hedging instrument are cointegrated, both specifications yield similar results, which depend on the hedge horizon.

Finally, Zhou (2016) extended the methodology in hedging performance by using most effective hedging performance of Real Estate Investment Trusts futures in order to examine the hedge ratios.

\section{DATA AND METHODOLOGY}

\subsection{Data}

Our analysis is based on data from international capital markets that refer to developed countries such as US and several core and peripheral EU economies such as Germany, Spain, Italy and Greece. This would enable us to detect possible inefficiencies throughout the comparative analysis. Daily data for the S\&P-500, DAX, FTSE/ATHEX-20, IBEX and PSI cash and futures prices are used from 4 January 2010 to 31 December 2015. When a holiday occurs on Thursday, Wednesday's observation is used in its place. Futures prices are always those of the nearby contract because it is the most liquid and active contract. To avoid thin markets and expiration effects (when futures contracts approach their settlement days, their trading volume decreases sharply), we rollover to the next nearest contract one week before the nearby contract expires. For the estimation of hedge ratios we used the period 2010-2014.

The international financial crisis, which was produced in the USA and expanded internationally, did not leave the euro countries intact. The European debt crisis, which intensified in the period 2010-2015, hit most of the southern countries, whose stock markets had a negative course against the German stock market and America. Table 1 shows that the markets with the highest capitalization, i.e. the 
DAX index and the S\&P index, are a positive instrument while the other markets present a negative medium that does not differ greatly from zero. FTSE / ATHEX20 index is the worst performing, with the exception of its negative trend, the highest Standard Deviation. This is also due to the country's inability to borrow from the Money Market because of excessive government debt.

Table 1. Summary Statistics

\begin{tabular}{|l|r|r|r|r|r|}
\hline Indexes/Futures & \multicolumn{1}{|c|}{$\begin{array}{c}\text { Number of } \\
\text { Observations }\end{array}$} & \multicolumn{1}{c|}{ Mean } & \multicolumn{1}{c|}{$\begin{array}{l}\text { Standard } \\
\text { Deviation }\end{array}$} & \multicolumn{1}{l}{ Skewness } & Kurtosis \\
\hline $\begin{array}{l}\text { DAX index } \\
\text { Spot }\end{array}$ & 1488 & 0.000473 & 0.013193 & -0.116881 & 5.109322 \\
\hline Future & 1488 & 0.000473 & 0.013036 & -0.155840 & 5.300520 \\
\hline $\begin{array}{l}\text { S\&P-500 index } \\
\text { Spot }\end{array}$ & 1488 & 0.000454 & 0.010123 & -0.317931 & 7.087520 \\
\hline Future & 1488 & 0.000456 & 0.010290 & -0.333898 & 7.613981 \\
\hline $\begin{array}{l}\text { IBEX index } \\
\text { Spot }\end{array}$ & 1467 & -0.000045 & 0.015698 & 0.426613 & 8.974296 \\
\hline $\begin{array}{l}\text { Future } \\
\text { PSI index }\end{array}$ & 1467 & -0.000235 & 0.013655 & 0.023012 & 6.371580 \\
\hline Fpot & 1467 & -0.000223 & 0.014460 & 0.290209 & 10.38443 \\
\hline $\begin{array}{l}\text { FTSE/ATHEX- } \\
\text { 20 index Spot }\end{array}$ & 1467 & -0.000852 & 0.027591 & 0.239800 & 6.866535 \\
\hline \begin{tabular}{l} 
Future \\
\hline
\end{tabular} & 1467 & -0.000803 & 0.029254 & 0.550955 & 10.69623 \\
\hline
\end{tabular}

\subsection{Methodology}

The main idea of hedging is to construct a portfolio using investments from the spot market and futures market which will drastically reduce its value fluctuations.

So, we will use a portfolio which has $C_{s}$ units of a long spot position and $C_{f}$ units of a short futures position. By $S_{t}$ and $F_{t}$ we will denote the spot and the futures prices at time $t$, respectively. The presence of futures contracts in the portfolio aims to reduce the fluctuations that a portfolio consisting of equities could experience. This portfolio called "hedged portfolio".

We denoted by $\Delta V_{h}$ the price change of the constructed hedged portfolio:

$$
\Delta V_{h}=C_{s} \Delta S_{t}-C_{f} \Delta F_{t}=C_{s}\left(\Delta S_{t}-h \Delta F_{t}\right)
$$

where

$\Delta S_{t}=S_{t+1}-S_{t}$ and $\Delta F_{t}=F_{t+1}-F_{t}$ are the price changes of spot and futures positions. Hedge ratio is the fraction of the short futures position over the long spot 
position, i.e. $h=C_{f} / C_{s}$. Hedging has as main objective to find and determine the optimal hedge ratio $h$.

Johnson (1960) derives the minimum-variance hedge ratio focusing in the portfolio risk. The measure of the risk in a portfolio is related with the variance of the price change of the hedged portfolio:

$$
\operatorname{Var}\left(\Delta V_{h}\right)=C_{s}^{2}\left[\operatorname{Var}\left(\Delta S_{t}\right)+h^{2} \operatorname{Var}\left(\Delta F_{t}\right)-2 h \operatorname{Cov}\left(\Delta S_{t}, \Delta F_{t}\right)\right]
$$

The minimum-variance hedge ratio is given by

$$
h^{*}=\frac{\operatorname{Cov}\left(\Delta S_{t}, \Delta F_{t}\right)}{\operatorname{Var}\left(\Delta F_{t}\right)}=\frac{\sigma_{s f}}{\sigma_{f}^{2}}=\rho \frac{\sigma_{s}}{\sigma_{f}}
$$

where

$\rho$ is the correlation coefficient between $\Delta S_{t}$ and $\Delta F_{t}$, and $\sigma_{\mathrm{s}}$ and $\sigma_{\mathrm{f}}$ are standard deviations of $\Delta S_{t}$ and $\Delta F_{t}$, respectively.

The estimation of the optimum hedge ratio is implemented applying several econometric models (Lee et al., 2009). Three models are applied in this paper that refers to conventional and also more advanced approaches:

i) The ordinary least squares (OLS) model,

ii) The error correction model (ECM) and

iii) The Autoregressive Distributed Lag (ARDL) cointegration model.

The general econometric model representing the relationship between spot prices and derivatives is the bivariate model of Pesaran (1997):

Assume that $S_{t}$ and $F_{t}$ are the spot price and futures price. Then, $\Delta S_{t}=S_{t}-S_{t-1}$ and $\Delta F_{t}=F_{t}-F_{t-1}$ respectively represent the changes of the prices of spot and futures positions. By $\Delta$ we denote the difference operator.

$$
\begin{aligned}
& \Delta S_{t}=\alpha_{s}\left(1-\rho_{s}\right)-\left(1-\rho_{s}\right) S_{t-1}+\gamma F_{t-1}+\varepsilon_{s, t} \\
& \Delta F_{t}=\alpha_{f}\left(1-\rho_{f}\right)-\left(1-\rho_{f}\right) F_{t-1}+\lambda S_{t-1}+\varepsilon_{f, t}
\end{aligned}
$$

and assume that

$$
\left(\begin{array}{l}
\varepsilon_{s, t} \\
\varepsilon_{f, t}
\end{array}\right) \sim \operatorname{iid}(0, \Sigma), \quad \Sigma=\left(\begin{array}{cc}
\sigma_{s}^{2} & \sigma_{s f} \\
\sigma_{s f} & \sigma_{f}^{2}
\end{array}\right)
$$

where

$\sigma_{s f}$ is the covariance between $\varepsilon_{s}$ and $\varepsilon_{f}$, and $\sigma_{s}^{2}$ and $\sigma_{f}^{2}$ are variances of $\varepsilon_{s}$ and $\varepsilon_{f}$, respectively.

In order to estimate the minimum variance hedge ratio we will apply ordinary least squares (OLS) technic, i.e. regression of price changes of the spot on the price changes of the futures. We assume that the spot and futures prices follow a pure random walk and assuming that $\rho_{s}=\rho_{f}=1, \gamma=\lambda=0$ we have: 


$$
\begin{aligned}
\Delta S_{t} & =\varepsilon_{s, t} \\
\Delta F_{t} & =\varepsilon_{f, t}
\end{aligned}
$$

If we assume that $\varepsilon_{s}$ and $\varepsilon_{f}$ are jointly normally distributed, we conclude

$$
\varepsilon_{s, t}=\left(\sigma_{s f} / \sigma_{f}^{2}\right) \varepsilon_{f, t}+v_{t}
$$

where

$\sigma_{s f} / \sigma_{f}^{2}$ represents the population coefficient of the regression of $\varepsilon_{s, t}$ on $\varepsilon_{f, t}$, and $v_{t}$ is distributed independently of $\varepsilon_{f, t}$. Then we could present the ordinary least squares model as follows:

$$
\Delta S_{t}=\alpha+\beta \Delta F_{t}+v_{t}
$$

(with $\beta=\sigma_{s f} / \sigma_{f}^{2}$ under the jointly normality condition). The estimation of $\beta$ will give the estimation of minimum variance hedge ratio, $h^{*}$,

Alternatively, according to the long-run equilibrium relationship between spot and futures prices we apply the error correction model. The condition for arbitrage connects spot and futures prices. Following this, it is natural to suppose that they cannot drift far apart in the long run. Therefore, if each series follows a random walk process, then we expect this two series to be cointegrated. We take the assumption that the spot price $S_{t}$ and futures price $F_{t}$ are unit-root processes and at the same time are co-integrated. Assuming that

$\left|\rho_{s}\right|<1, \rho_{f}=1, \gamma \neq 0, \lambda=0$ or $\rho_{s}=1,\left|\rho_{f}\right|<1, \gamma=0, \lambda \neq 0$ we have:

$$
\Delta S_{t}=\alpha_{s}\left(1-\rho_{s}\right)-\left(1-\rho_{s}\right) S_{t-1}+\gamma F_{t-1}+\varepsilon_{s, t}
$$

and

$$
\Delta F_{t}=\varepsilon_{f, t}
$$

We write $\varepsilon_{s, t}=\beta \varepsilon_{f, t}+v_{t}$ and use this expression to rewrite the previous equations as:

$$
\Delta S_{t}=\alpha+\theta z_{t-1}+\beta \Delta F_{t}+v_{t}
$$

where

$$
\alpha=\alpha_{s}\left(1-\rho_{s}\right), \theta=-\left(1-\rho_{s}\right), \beta=\left(\sigma_{s f} / \sigma_{f}^{2}\right) \text { and } z_{t-1}=S_{t-1}-\gamma /\left(1-\rho_{s}\right) F_{t-1} \text { is }
$$

referred to as the error-correction term at time $t$.

We will apply the least squares method to the model. The estimation of $\beta$ corresponds to the optimal hedge ratio $h^{*}$. If the spot price and futures price series are found to be cointegrated, then the hedge ratio can be estimated in two steps (Ghosh, 1993). The first step involves the estimation of the following cointegrating regression:

$$
S_{t}=a+b F_{t}+e_{t}
$$


The second step involves the estimation of the following error correction model:

$$
\Delta S_{t}=\mu+\lambda u_{t-1}+\beta \Delta F_{t}+v_{t}
$$

where

$u_{t}$ is the residual series from the cointegrating regression in Equation (3). The estimation of $\beta$ from (4) will give the estimation of the hedge ratio.

The Autoregressive Distributed Lag cointegration model studied first by Pesaran (1997). He stated that the existence of a long-run relationship between the spot price $S_{t}$ and futures price $F_{t}$ does not depend on whether $F_{t}$ is I(1) (i.e. $\rho_{f}=1$ ).

If we suppose that there exists a single long-run relationship between $S_{t}$ and $F_{t .}$, then it have to be $\left|\rho_{s}\right|<1, \gamma \neq 0, \lambda=0$ or $\left|\rho_{f}\right|<1, \lambda \neq 0, \gamma=0$. We assume that $\left|\rho_{s}\right|<1, \gamma \neq 0, \lambda=0$ (without loss of generality). Then we have that:

$$
\Delta F_{t}=\alpha_{f}\left(1-\rho_{f}\right)-\left(1-\rho_{f}\right) F_{t-1}+\varepsilon_{f, t}
$$

Since we supposed that $\varepsilon_{s}$ and $\varepsilon_{f}$ are jointly normally distributed (1), we have from (2):

$$
\Delta S_{t}=\alpha_{1}+\alpha_{2} S_{t-1}+\alpha_{3} F_{t-1}+\beta \Delta F_{t}+v_{t}
$$

where

$$
\begin{aligned}
& \alpha_{1}=\alpha_{s}\left(1-\rho_{s}\right)-\alpha_{f}\left(\sigma_{s f} / \sigma_{f}^{2}\right)\left(1-\rho_{f}\right), \alpha_{2}=-\left(1-\rho_{s}\right) \\
& \alpha_{3}=\left[\gamma+\left(\sigma_{s f} / \sigma_{f}^{2}\right)\left(1-\rho_{f}\right)\right] \text { and } \\
& \beta=\left(\sigma_{s f} / \sigma_{f}^{2}\right) \text {. At this point, we could mention that Equation (5) is a single- }
\end{aligned}
$$
step process. This means that it is not the same from the two-step method used by the Equation (4).

\section{RESULTS}

Table 2 presents the results of the estimate hedge ratio based on the methodology described above.

Table 2. Estimated Hedge Ratios

\begin{tabular}{|l|l|l|}
\hline \multicolumn{1}{|c|}{ Index } & & Per Day \\
\hline DAX index & $\beta^{\text {OLS }}$ & 1.004252 \\
\hline & $\beta^{E C M}$ & 1.015479 \\
\hline S\&P 500 index & $\beta^{\text {ARDL }}$ & 1.015949 \\
\hline & $\beta^{\text {OLS }}$ & 0.958953 \\
\hline & $\beta^{E C M}$ & 0.956242 \\
\hline & $\beta^{\text {ARDL }}$ & 0.963976 \\
\hline
\end{tabular}




\begin{tabular}{|l|l|l|}
\hline \multicolumn{1}{|c|}{ Index } & & Per Day \\
\hline FTSE/ATHEX-20 index & $\beta^{\text {OLS }}$ & 0.881013 \\
\hline & $\beta^{E C M}$ & 0.868288 \\
\hline & $\beta^{\text {ARDL }}$ & 0.896831 \\
\hline PSI index & $\beta^{\text {OLS }}$ & 0.888204 \\
\hline & $\beta^{E C M}$ & 0.882088 \\
\hline IBEX index & $\beta^{\text {ARDL }}$ & 0.899438 \\
\hline & $\beta^{\text {OLS }}$ & 0.980981 \\
\hline & $\beta^{E C M}$ & 0.985129 \\
\hline & $\beta^{\text {ARDL }}$ & 0.985811 \\
\hline
\end{tabular}

We note that the hedge ratio is lower than the unit for all markets except for the DAX index, which is close to 1 . Moreover, the hedge ratio in all methods is similar except Greece's index showing some variations. With regard to the risk hedging strategy for an administrator, the ARDL model can provide the most effective risk hedging.

\subsection{Unit root test}

To make sure that the time series data is stationary, we used the augmented Dickey-Fuller test (Dickey \& Fuller, 1981) and PP test (Phillips \& Perron, 1988). Both tests appeared in Table 3 and indicated that the first order differences of the spot and the futures prices in the five markets generate stationary series at the $1 \%$ significance level.

Table 3. Results of the Unit-Root Tests on Spot and Futures Prices

\begin{tabular}{|l|l|l|l|}
\hline & & ADF & PP \\
\hline Dax index & Spot & $-40,8868^{* *}$ & $-41,1653^{* *}$ \\
\hline & Futures & $-26,8623^{* *}$ & $-42,2563^{* *}$ \\
\hline S\&P index & Spot & $-31,4564^{* *}$ & $-43,4556^{* *}$ \\
\hline & Futures & $-45,2455^{* *}$ & $-45,3669^{* *}$ \\
\hline FTSE-20 index & Spot & $-18,2566^{* *}$ & $-37,2567 * *$ \\
\hline & Futures & $-19,5897 * *$ & $-37,4577 * *$ \\
\hline IBEX index & Spot & $-20,1445^{* *}$ & $-40,1245^{* *}$ \\
\hline & Futures & $-17,5461 * *$ & $-43,5778^{* *}$ \\
\hline PSI index & Spot & $-11,2489 * *$ & $-39,2456^{* *}$ \\
\hline & Futures & $-12,2899 * *$ & $-40.4877 * *$ \\
\hline
\end{tabular}

*indicates significance at $5 \%$ level, $* *$ indicates significance at $1 \%$ level. 


\subsection{Hedge ratios and hedging effectiveness measures}

A popular measure of hedging effectiveness was created by Ederington (1979) and since applied in numerous empirical studies, is the percentage reduction in variance:

$$
\text { Variance_Re duction }=\frac{\operatorname{Var}\left(\Delta S_{t}\right)-\operatorname{Var}\left(R_{H, t}\right)}{\operatorname{Var}\left(\Delta S_{t}\right)}
$$

which compares the variance of the returns of the hedged portfolios $\operatorname{Var}\left(R_{H, t}\right)$ to the variance of the unhedged positions $\operatorname{Var}\left(\Delta S_{t}\right)$.

Hedging performance, measured using variance reduction, is calculated out-ofsample using data from 01/01/2015 - 31/12/2015. The results of the variance reduction in the out of sample analysis summarizes in the table 4.

Table 4. Hedging effectiveness results

\begin{tabular}{|l|r|r|r|}
\hline & Ordinary Least Square & Error Correction Model & ARDL Model \\
\hline DAX index & $98,084 \%$ & $98,037 \%$ & $98,094 \%$ \\
\hline S\&P index & $93,524 \%$ & $93,516 \%$ & $93,635 \%$ \\
\hline FTSE-20 index & $89,766 \%$ & $89,593 \%$ & $90,936 \%$ \\
\hline IBEX index & $97,172 \%$ & $97,154 \%$ & $97,693 \%$ \\
\hline PSI index & $94,017 \%$ & $93,919 \%$ & $94,476 \%$ \\
\hline
\end{tabular}

We notice that the largest variance reduction is achieved in the DAX index while the lowest in the FTSE-20 index. This means that for DAX we have higher hedging ratios. The ARDL Model also achieves the largest variance reduction across all stock indices.

\section{CONCLUSION}

This paper examines different methods of hedging in American and European stock portfolios with the help of futures contracts. Hedge ratios are calculated using three alternative econometric methods: the Ordinary Least Square Model (OLS), the Error Correction Model (ECM), and the Autoregressive Distributed Lag (ARDL) cointegration model.

It also evaluates the effectiveness of alternative hedging methods based on variance reduction. The results show that Autoregressive Distributed Lag cointegration model is more efficient than the fixed hedge ratios in terms of minimizing the risk and this superior performance of the advanced econometric models is pronounced when analyzing data from the periphery capital markets. 


\section{REFERENCES}

Baillie, R. T., \& Myers, R. J. (1991). Bivariate GARCH Estimation of the Optimal Commodity Futures Hedge. Journal of Applied Econometrics, 6(2), 109-124. https://doi.org/10.1002/jae.3950060202

Cecchetti, S. \& Cumby, R. (1988). Estimation of the Optimal Futures Hedge. The Review of Economics and Statistics, 70(4), 623-630.

Chen, S.S., Lee, C.F., \& Shrestha, K. (2001). On a Mean-Generalized Semivariance Approach to Determining the Hedge Ratio. Journal of Futures Markets, 21, 581-598. https://doi.org/10.1002/fut.1604

Chou, W., Denis, K., \& Lee, C. (1996). Hedging with the Nikkei Index Futures: The Convential Model versus the Error Correction Model. The Quarterly Review of Economics and Finance, 36(4), 495-505. https://doi.org/10.1016/S1062-9769(96)90048-4

Dickey, D.A., \& Fuller, W.A. (1981). Likelihood Ratio Statistics for Autoregressive Time Series with a Unit Root. Econometrica, 49, 1057-1072. https://doi.org/10.2307/1912517

Ederington, L.H. (1979). The Hedging Performance of the New Futures Markets. The Journal of Finance, 34(1), 157-170. https://doi.org/10.1111/j.1540-6261.1979.tb02077.x

Ghosh, A. (1993). Cointegration and Error Correction Models: Intertemporal Causality between Index and Futures Prices. Journal of Futures Markets, 13, 193-198.

Herbst, A. F., Kare, D. D., \& Caples, S. C. (1989). Hedging Effectiveness and Minimum Risk Hedge Ratios in the Presence of Autocorrelation: Foreign Currency Futures. Journal of Futures Markets, 9(3), 185-197. https://doi.org/10.1002/fut.3990090302

Johnson, L. L. (1960). The Theory of Hedging and Speculation in Commodity Futures. Review of Economic Studies, 27, 139-151.

Juhl, T., Kawaller, I. G., \& Koch, P. D. (2012). The Effect of the Hedge Horizon on Optimal Hedge Size and Effectiveness when Prices are Cointegrated. Journal of Futures Markets, 32(9), 837-876. https://doi.org/10.1002/fut.20544

Lee, C.F., Lin, F.L., Tu, H.C., Chen, M.L. (2009). Alternative Methods for Estimating Hedge Ratio: Review, Integration and Empirical Evidence. Working paper, Rutgers University.

Lee, C. F., Wang, K., \& Chen, Y. L. (2009). Hedging and Optimal Hedge Ratios for International Index Futures Markets. Review of Pacific Basin Financial Markets and Policies, 12(04), 593-610. https://doi.org/10.1142/S0219091509001769

Lien, D., \& Luo, X. (1993). Estimating Multiperiod Hedge Ratios in Cointegrated Markets. Journal of Futures Markets, 13(8), 909-920. https://doi.org/10.1002/fut.3990130808

Lien, D., \& Luo, X. (1994). Multiperiod Hedging in the Presence Of Conditional Heteroskedasticity. Journal of Futures Markets, 14(8), 927-955. https://doi.org/10.1002/fut.3990140806

Lien, D., \& Tse, Y.K. (1998). Hedging Time-Varying Downside Risk. Journal of Futures Markets, 18, 705722. https://doi.org/10.1002/(SICI)1096-9934(199809)18:6<705::AID-FUT4>3.0.CO;2-R

Lien, D., \& Tse, Y.K. (2000). Hedging Downside Risk With Futures Contracts. Applied Financial Economics, 10, 163-170. https://doi.org/10.1080/096031000331798

Norden, L. (2006). Does an Index Futures Split Enhance Trading Activity and Hedging Effectiveness of the Futures Contract? Journal of Futures Markets, 26, 1169-1194. https://doi.org/10.1002/fut.20237

Park, H. Y., \& Bera, A. K. (1987). Interest-Rate Volatility, Basis Risk and Heteroscedasticity in Hedging Mortgages. Real Estate Economics, 15(2), 79-97. https://doi.org/10.1111/1540-6229.00420

Pennings, J.M.E., \& Meulenberg, M.T.G. (1997). Hedging Efficiency: a Futures Exchange Management Approach. Journal of Futures Markets, 17, 599-615. https://doi.org/10.1002/(SICI)10969934(199708)17:5<599::AID-FUT5>3.0.CO;2-A

Pesaran, M. H. (1997). The Role of Economic Theory in Modelling the Long Run. Economic Journal, 107, 178-191.

Phillips, P., \& Perron, P. (1988). Testing Unit Roots in Time Series Regression. Biometrika, 75, 335-346. https://doi.org/10.2307/2336182

Sah, A. N., \& Pandey, K. K. (2011). Hedging Effectiveness of Index Futures Contract: The Case of S\&P CNX Nifty. Global Journal of Finance and Management, 3(1), 77-89.

Shalit, H. (1995). Mean-Gini hedging in futures markets. Journal of Futures Markets, 15(6), 617-635. https://doi.org/10.1002/fut.3990150603

Switzer, L.N. \& El-Khoury, M. (2007). Extreme Volatility, Speculative Efficiency, and the Hedging Effectiveness of the Oil Futures Markets. Journal of Futures Markets, 27(1), 61-84. https://doi.org/10.1002/fut.20235

Wang, J., \& Hsu, H. (2010). Hedge Ratio Stability and Hedging Effectiveness of Time-Varying Hedge Ratios in Volatile Index Futures Markets: Evidence from the Asian Financial Crisis. Asia-Pacific Journal of Financial Studies, 39(5), 659-686. https://doi.org/10.1111/j.2041-6156.2010.01026.x 
Zhou, J. (2016). Hedging Performance of REIT Index Futures: a Comparison of Alternative Hedge Ratio Estimation Methods. Economic Modelling, $\quad$ 52(PB), https://doi.org/10.1016/j.econmod.2015.10.009

\section{AUTHORS' SHORT BIOGRAPHIES}

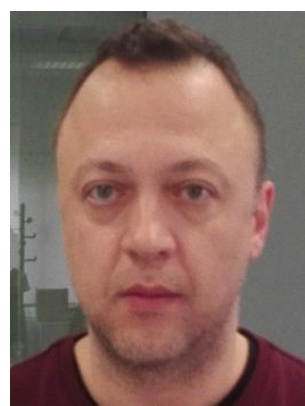

Alexandros Koulis is a Lecturer at the Department of Business Administration of the Technological Educational Institution of Ionian Islands in Greece. He received the Ph.D. degree in finance from the University of Central Greece. His research interests include applications in financial markets.

E-mail: koulisal@gmail.com

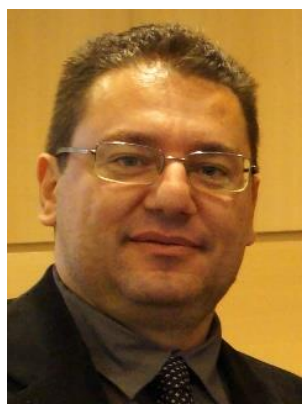

George Kaimakamis is an Associate Professor of Mathematics in Hellenic Army Academy in Greece. He received the Ph.D. degree in mathematics from the University of Patras in 2003. His research interests include applications of mathematics.

E-mail:gmiamis@sse.gr,gmiamis@gmail.com

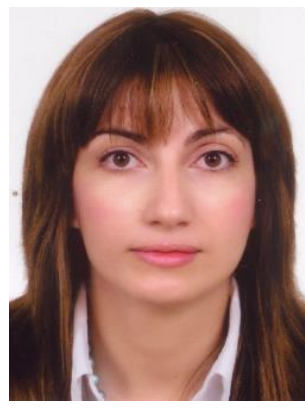

Christina Beneki is an Associate Professor of Mathematics and Statistics and Head of the Department of Business Administration of the Technological Educational Institution of Ionian Islands in Greece. She received the Ph.D. degree in mathematics from the University of Patras. Her current research interests include applications of statistical methods in business, economics and tourism.

E-mail: benekic@teiion.gr 